\title{
PRESENCIA, HUELLA Y REGISTRO EN EL VÍDEO DE DANZA. APUNTES A PARTIR DE SUITE FOR TWO (MERCE CUNNINGHAM, 1960)
}

\author{
PRESENCE, TRACE AND RECORDING IN VIDEO DANCE. \\ NOTES FROM SUITE FOR TWO (MERCE CUNNINGHAM, 1960)
}

\author{
Gabriel VILLOTA TOYOS \\ Universidad del País Vasco / Euskal Herriko Unibertsitatea \\ gabriel.villota@ehu.eus
}

Resumen: La coreografía que podemos ver sobre un escenario y el registro de dicha coreografía sobre cualquier soporte audiovisual son obras diferentes, aunque partan de un mismo material original. Más allá del carácter factográfico, denotativo y documental de este tipo de trabajos, proponemos que una vez estas imágenes quedan encuadradas por la cámara y articuladas mediante la sintaxis del montaje, surgen nuevas posibilidades interpretativas que tiene más bien que ver con las propiedades connotativas del lenguaje. Para apoyarnos en la argumentación de esta hipótesis nos basaremos en el concepto derridiano de "huella" como generador del "sentido" propio de la escritura, frente a la pura "presencia".

Palabras clave: Videodanza. Registro. Artes performativas. Suite for Two. Merce Cunningham.

Abstract: The choreography we see on stage and the recording of this choreography on any audiovisual media are different works, although departing from the same original material. Beyond the factographic, denotative and documentary character of such a work, we propose that once these images are framed by the camera and articulated by the syntax of editing, there are new interpretative possibilities that has rather to do with the use of connotative language. To rely on the argument of this hypothesis we will part from the Derridean concept of "trace" as a generator of meaning, compared to pure "presence".

Key Words: Videodance. Recording. Performative Arts. Suite for Two. Merce Cunningham. 
Sabemos que la fenomenología quiere estudiar lo inmanente.

(Javier San Martín, 2008).

Ningún gesto nace de sí mismo. Ningún acto se fragua en el vacío.

Pratittya samutpada: todo lo que adviene es condicionado.

(Chantal Maillard, 2015).

Otra definición del plano-contraplano: soportamos aquello difícil de soportar porque siempre aparece velado, con una mitad oculta que, sin embargo, sigue estando presente.

(Harun Farocki, 2013).

\section{INTRODUCCIÓN}

Después de más de un siglo de imágenes de cuerpos en movimiento hoy en día sigue vivo el debate sobre si las películas o los vídeos recogen con fidelidad la supuesta verdad inherente a las prácticas performativas en directo que tienen al cuerpo humano como elemento central: principalmente las relacionadas con la danza contemporánea y la performance artística. En definitiva estamos ante una cuestión de raigambre fenomenológica, pero también semiótica, en la que se trata de dilucidar si la experiencia de la presencia es algo así como una experiencia de primer orden, respecto de la cual el registro sería una suerte de experiencia subsidiaria (y a su vez dadora de verosimilitud), o bien, por el contrario, si el concepto de huella, por sí mismo, y en tanto que ejercicio de inscripción y escritura, puede constituir de suyo un acceso directo a lo real.

La coreografía que podemos ver en directo, sobre un escenario, y el registro de dicha coreografía sobre cualquier soporte audiovisual son, desde esta perspectiva, obras de arte diferentes, aunque partan de un mismo material original. Por tanto cualquier tipo de discusión sobre el correcto reflejo de la intención o carácter de la obra original o no o la posible verdad o fidelidad subyacente a dichos productos audiovisuales estarían fuera de lugar. Más allá del carácter factográfico, denotativo y documental que usualmente se asigna a este tipo de trabajos, proponemos que una vez estas imágenes-cuerpo quedan encuadradas por la cámara y articuladas mediante la sintaxis del montaje (como veremos en este caso, fundamentalmente por la articulación del plano-contraplano), surgen nuevas posibilidades interpretativas y de lectura que tiene más bien que ver con las propiedades connotativas del lenguaje.

Para apoyarnos en la argumentación de esta hipótesis nos basaremos en el concepto derridiano de huella o inscripción, como vector generador del sentido propio de la escritura, frente a la pura presencia, interiorizada durante siglos de filosofía occidental como una suerte de experiencia más auténtica. 


\section{2. "SER UN CUERPO": FENOMENOLOGÍA DE LA PRESENCIA EN EDMUND HUSSERL Y EN LAS ARTES DE VANGUARDIA}

Marquemos pues, para iniciar este recorrido, un punto cero. Por ejemplo, la pura presencia, inmanente, de un cuerpo que baila en silencio. Una "metafísica de la presencia", que diría Derrida, es justamente lo que caracteriza en buena medida el proyecto fenomenológico de Husserl en sus Investigaciones lógicas: proyecto que fuera otro intento de marcar un punto cero, en este caso aplicando un programa reductivo a la historia de la metafísica. Ese punto cero se basa en la famosa epojé o reducción fenomenológica, según la cual a partir de ese momento se hace necesario desde un punto de vista metodológico "poner entre paréntesis lo dado para que aparezca más claramente el modo de darse". Al poner entre paréntesis, en realidad lo que hacemos es poner "en suspenso la afirmación de realidad del mundo" (Cruz, 2002): pero esta suerte de "suspensión de la credulidad" no tiene como objetivo en sí "dudar de la realidad del mundo", sino que más bien lo que trata es de comprender "las vivencias en toda su pureza, esto es, sin vinculación a un contexto natural causal, ya sea físico o psicológico" (Cruz, 2002. La cursiva es nuestra).

Si, siguiendo a Husserl, aplicáramos la reducción fenomenológica como método de acercamiento a las prácticas artísticas que aquí nos interesan (las de los cuerpos que bailan sobre la escena), y de esta manera nos quedáramos por tanto exclusivamente frente a "la esfera del yo puro y de la conciencia pura", sería fácil ver la conexión que se establece de inmediato entre este giro epistemológico basado en la "metafísica de la presencia" referida, y la defensa a ultranza, casi integrista, que algunos hacen de las artes performativas (danza, música o teatro) vividas in situ, en esa compartición del aquí y el ahora entre performers y público característico de las mismas, frente a cualquier clase de experiencia mediada de las mismas, esto es, su registro en cine, audio o vídeo: "lo propio del impulso fundacional de la empresa husserliana es precisamente su voluntad de volver a las cosas mismas y que ese regreso puede ser interpretado como un rechazo de toda opción metafísica" (Cruz, 2002):

Operando en la epojé nos convertimos en espectadores completamente desinteresados del mundo, del mundo en cuanto subjetivo-relativo (esto es, de aquel en que se desarrolla nuestra vida en común en su conjunto con sus esfuerzos, sus cuidados, sus operaciones) (Husserl, 1991).

Pero esta revalorización de la presencia no es la única cuestión destacable en la proximidad que vamos a encontrar entre las líneas de fuga de la Fenomenología y las prácticas artísticas: puesto que, como explica Manuel Cruz, de resultas de todo ese 
desandar los caminos trillados por la metafísica "el fenomenólogo emprende el camino que le dirige a las cosas mismas", para así acabar encontrándose con otros cuerpos: esta instancia corporal en la fenomenología se inscribe en el hecho de entender que "somos un cuerpo", y no que "tenemos un cuerpo".

Esa consciencia de ser un cuerpo es algo que ha sido especialmente importante en todas las artes desde que se abre ese amplio periodo que llamamos modernidad y que se inicia con el Romanticismo, pero muy particularmente a partir de comienzos del siglo $\mathrm{XX}$, justo en contemporaneidad con la aparición de la fenomenología, con el surgimiento de las Artes de Vanguardia: y aquí ya no solamente en relación a las artes performativas, donde obviamente la identidad con el cuerpo del artista (actor, bailarín) viene de suyo, sino también respecto al ámbito de las llamadas Artes Plásticas o Visuales, donde ya desde el futurismo o el dadaísmo, y el surrealismo después, esta nueva conciencia de la corporalidad estará muy presente.

Creemos que, en relación a nuestra investigación, será relevante subrayar cómo precisamente esta conciencia de ser un cuerpo, a la que apunta tanto la fenomenología, desde su impugnación al edificio de la metafísica, como el arte de vanguardia, en su impugnación al edificio de la representación, coincide con la obsesión de ambas corrientes (fenomenología y vanguardia artística) por definir ese punto cero donde todo recomienza. La idea de tabula rasa, tan cara al proyecto de la modernidad en su conjunto, es también la que subyace a la operación de la epojé comentada arriba como programa de reducción y búsqueda de la esencia.

\section{UNA BREVE REFLEXIÓN A PROPÓSITO DE LA HUELLA, ENTRE LEVINAS Y DERRIDA}

Emmanuel Levinas (2000) comenzaba su disertación sobre la huella, reflexionando a partir de la imagen del rostro como "huella del otro", en el marco precisamente de la conceptualización sobre ese otro que caracterizó buena parte de su filosofía. Una idea interesante que ya plantea Levinas desde el comienzo es la compleja relación de la huella con el concepto de signo, cuando dice que la huella "no es un signo como otros", aunque obviamente también desempeña ese papel: "el cazador sigue la huella de la caza mayor, que refleja la actividad y la dirección del animal que quiere alcanzar" (Levinas, 2000). Pero, ¿por qué no es entonces un signo cualquiera? Porque, a diferencia de otros signos, dice Levinas, la huella "perturba el orden del mundo": dejar una huella significa, en este sentido, "pasar, partir, absolverse" (Levinas, 2000). La huella queda como testimonio del ser, registro de su "pesadez", "fuera de sus actos y de su lenguaje": una pesadez que no se debe en ningún caso a su presencia, fugaz, sino a su "irreversibilidad", que como dijimos 
afecta de manera irrevocable al mundo. La huella representaría, en este sentido, "la indelebilidad misma del ser".

El motivo por el que la huella se convierte en algo indeleble tiene también que ver con otra característica que Levinas cita, y es por su peculiar conjunción de las coordenadas espacio-temporales: la huella, como él dice, "es la inserción del espacio en el tiempo", de tal modo que "aquello que, propiamente hablando, no ha estado jamás aquí" se hace presente entre nosotros. Y la huella, obviamente, es también y sobre todo significado, interpretación del que la mira: "sin el hombre que ha tenido en la mano la piedra, la estría es sólo un efecto" (Levinas, 2000). Sin esa mirada que la escruta, lo que llamamos huella sería sólo efecto físico, producto del roce, de la emulsión, del desgaste, etc.

"La huella es, en efecto, el origen absoluto del sentido en general. Lo cual equivale a decir, una vez más, que no hay origen absoluto del sentido en general", decía Jacques Derrida, precisamente a partir de su lectura cruzada de Husserl con Levinas. Asumir en este sentido la materialidad de una inscripción (escrita, sonora, visual: tanto da), en tanto que huella originaria de un fenómeno, supone de hecho mostrar cómo "la presencia, que está en la base de la interioridad ideal de la fenomenología, está asediada por una diferencia original" (Pávez, 2011), que tiene que ver con la idea de alteridad; y esta diferencia (différance), "previa a toda determinación de contenido", no es otra cosa que "la huella (pura)", que no puede en ningún caso desligarse de la presencia: puesto que "lo que tal diferencia moviliza es la inscripción como condición material de los objetos ideales" (Pávez, 2011), es decir, su misma "condición de posibilidad" (Derrida, 1971):

Si la huella desbarata la naturalización, es porque no participa de las oposiciones y jerarquías tranquilizadoras como presencia/ausencia, verdad/ apariencia, inteligible/sensible, forma/materia, ideal/empírico, naturaleza/ técnica, palabra/escritura. Se pone en marcha la deconstrucción del fonologocentrismo que relaciona de manera inmediata y natural el logos con la voz, la foné que dice el sentido de la verdad. Allí, la huella es inscripción originaria cuyo rastro indica que no hay origen uno yúnico del sentido, sino un 'carácter inmotivado' (Pávez, 2011).

Así las cosas, y en lo que a nosotros concierne, lo que la propuesta de Derrida sugiere es que podemos pensar en la filmación de la danza, en tanto que diferencia (différance) sustancial, como huella pura, que deviene acontecimiento o fenómeno en sí misma; y no tan solo como mera sombra, huella o registro de determinados fenómenos (la danza), tal y como convencionalmente ha venido siendo interpretada. 


\section{LAS FILMACIONES DE ACTUACIONES EN DIRECTO O EVENTOS ESPECIALES CON REALIZACIÓN MULTICÁMARA EN EL TRABAJO DE MERCE CUNNINGHAM (1960-1968)}

Diferentes momentos a lo largo de la historia del arte, el cine y la danza contemporáneas se han convertido en hitos singulares desde los que observar este doble comportamiento de la relación entre las prácticas performativas y las de registro: pero nos interesará detenernos aquí en particular en el trabajo audiovisual del coreógrafo Merce Cunningham, y de forma muy especial en un precedente de las primeras filmaciones de actuaciones en directo o eventos especiales con realización multicámara que se produjeron entre 1960 y 1968. Y es que efectivamente, mucho antes de que las colaboraciones estables de los realizadores Charles Atlas y Elliot Caplan se convirtieran en parte fundamental de la compañía de Merce Cunningham (Villota Toyos, 2015), algunos trabajos de este ya habían sido filmados y/o retransmitidos a lo largo de la década de los sesenta: varios de ellos aparecen catalogados como parte de una serie de emisiones televisivas realizadas en Suecia, Finlandia y Alemania.

Todas ellas comparten por lo general una serie de rasgos formales específicos que tienen que ver de un modo $u$ otro con un cierto tono primitivo que caracteriza todo este primer periodo: $y$ utilizamos este concepto no tanto porque fueran primitivos ni los referentes formales de las coreografías, ni tampoco los recursos audiovisuales utilizados para el registro, sino por la falta de definición en los objetivos, de conciencia en el uso de estos medios y de capacidad para articular conjuntamente los dos registros expresivos, a saber, danza y cine, o danza y televisión.

Aún así, incluso desde esta simplicidad que en tanto escritura audiovisual tienen estas piezas, en general podemos advertir también en ellas una clara resistencia a verse reducidas a simples huellas espectrales de lo que se suponen eran sus originales, las que podríamos definir como piezas presenciales en escena. Por todo ello, convendríamos con Derrida en la importancia que tiene otorgar una entidad propia, en cuanto que escritura, a estas huellas o registros que son las filmaciones, más allá de su mera subordinación a la coreografía:

La escritura ya no es solamente el auxiliar mundano y mnemotécnico de una verdad cuyo sentido de ser prescindiría, en símismo, de toda consignación. No solo la posibilidad o la necesidad de encarnarse en una grafía ya no es extrínseca y fáctica respecto a la objetividad ideal: es la condición sine qua non de su consumación interna. Mientras no está grabada en el mundo, o más bien, mientras no pueda estarlo, mientras no sea capaz de presentarse en una 
encarnación que, en la pureza de su sentido, sea más que una señalización o un ropaje, la objetividad ideal no se halla plenamente constituida. El acto de escritura es pues, la más alta posibilidad de toda constitución (Derrida, 2000: 86).

Y es que este es el punto de vista que no queremos perder a lo largo de todo nuestro acercamiento analítico, pues incluso cuando calificamos estos trabajos como primitivos o poco conscientes en relación a los medios utilizados, su capacidad intrínseca para generar sentido, en tanto que estructuras de lenguaje, va a permanecer igualmente inalterable.

Lo paradójico es que esa función meramente mnemotécnica a la que hace referencia Derrida en su texto es precisamente la que en un principio Cunningham, como tantos otros coreógrafos, buscaría en el audiovisual, desde ese primitivismo o ingenuidad de pensarlo desde una perspectiva puramente instrumental y factográfica:

\section{(...) caí en la cuenta de que tenía que existir una fuerte conexión entre la} danza y la televisión porque la danza es visual y en cuanto se hizo posible ver lo que se había filmado inmediatamente después de grabarlo, vi que sería interesante para la danza (Merce Cunningham¹ \& Jacqueline Lesschaeve, 2009: 222).

Pero como decíamos al comienzo de este apartado, ya incluso antes de que Cunningham tuviera ocasión de hacer estas reflexiones (unidas obviamente, como se colige de sus palabras, a la aparición de la tecnología portátil y en soporte magnético a finales de los años sesenta), algunos trabajos suyos habían venido siendo filmados o retransmitidos por televisión. E incluso antes de que se realizarán las piezas que fueron emitidas por las citadas estaciones de televisión del norte de Europa, nos encontramos con esta otra referencia, de las que apenas se dispone de información: se trata de la obra videográfica titulada Suite for Two (1960).

\section{SUITE FOR TWO (1960). DESCRIPCIÓN Y ANÁLISIS DE LA PIEZA}

Como indicábamos más arriba, Suite for Two es un programa televisivo del año 19601del que apenas hay ninguna referencia en la extensa bibliografía generada alrededor de la obra y la figura de Merce Cunningham: ni siquiera en el exhaustivo

1 Choreography Merce Cunningham. Music John Cage. Costumes Robert Rauschenberg. First Performance Date: May 18, 1956. First Performance Venue: University of Notre Dame, South Bend, IN. 
libro de David Vaughan (1997) consagrado a la vida y obra del coreógrafo. Por suerte, su registro audiovisual sin embargo aparece íntegro en la página web de la Fundación Merce Cunningham Trust. En efecto, el conocimiento que hemos tenido de esta pieza se debe a su incorporación dentro de la sección "Capsules" que la Merce Cunningham Trust ha desarrollado para Internet, y donde pueden ser consultadas numerosas obras audiovisuales de Merce Cunningham, así como otro tipo de documentación adicional en torno a su extensa obra².

La única referencia que allí tenemos de su producción (de indudable factura televisiva en términos estilísticos) es el nombre de una compañía, "Universal Video", en los créditos. Como decíamos más arriba, los contenidos se basan en la adaptación para dos bailarines que Cunningham en su día hiciera de Suite for Five (por ello solo las partes correspondientes a los dos solos y al dueto serán registradas ${ }^{3}$ ), y que ya había presentado en algunos lugares con este otro formato. La composición e interpretación de la música para piano, como será habitual en esos años, corresponde a John Cage y David Tudor. Por lo demás, y aunque en el catálogo de la Merce Cunningham Trust aparece bajo el único título de Suite for Two, la grabación que está disponible a través del servicio Capsules consta en realidad de dos piezas diferentes, que al parecer fueron interpretadas y registradas en continuidad por el estudio belga Universal Video, el 11 de octubre de 19604: se trata de por un lado de Suite for two, y por otro de lo que en realidad

2 Es muy recomendable, para cualquier estudioso o aficionado, la consulta de la página web de la fundación ( $h t t p: / / m e r c e c u n n i n g h a m . o r g /$ ), así como en particular la sección denominada "Capsules" ( $h t t p: / /$ dancecapsules.mercecunningham.org), donde se incluye mucha información sobre las coreografías más importantes de Merce Cunningham, incluyendo grabaciones íntegras de sus más importantes vídeos y películas (http://dancecapsules.mercecunningham.org/?8080ed).

3 "This dance was created by adding a trio, a duet and a quintet to Cunningham's earlier Solo Suite in Space and Time. By 1958, the original piece had been modified so that Cunningham's five solos were reduced to three, and a solo for Carolyn Brown was added. The classic purity and tranquility of Suite for Five is acknowledged in the program note, which read, "The events and sounds of this ballet revolve around a quiet center, which though silent and unmoving, is the source from which they happen."The music, Cage's Music for Piano, and the choreography, relied on the imperfections in paper and on chance operations, to determine both the musical composition and the movement of the ballet. Robert Rauschenberg designed the earth-toned leotards, with lighting by Beverly Emmons" (David Vaughan; extracto de la web).

4 Información obtenida en intercambio epistolar con la directora de la fundación, Lynn Wichern, quién exactamente nos escribió lo siguiente al respecto: "In 1960 on October 11th "Suite for Two" and "Music Walk for Dancers" was recorded at Universal video in Belgium. "Suite for Two" (the duet portion of "Suite for Five") was created for performances at the University of Pittsburgh on May 21, 1958. Later that year it was filmed at Studio Hamburg, an NDR (Norddeutscher Rundfunk) production along with "Changeling" and a duet from "Spring Weather and People". That film is labeled "Cunningham Ballett 1958" with Studio Hamburg". 
creemos que es tan solo un fragmento también de la pieza Music Walk for Dancers, es decir la versión coreografiada de la obra musical de John Cage Music Walk5.

Respecto a las imágenes, lo más destacable es la composición del plano principal, en el que los bailarines (primero una; luego el otro; finalmente ambos) al fondo de la escena tienen tanta importancia como el pianista en primer plano, así como las sombras de los dos cuerpos proyectadas en la pared de atrás. Parecería este plano hacer referencia a aquella idea del cineasta alemán Hartmut Bitomsky comentada por el también cineasta Harun Farocki, según la cual "primero existía un espacio filmado por la cámara en un espacio general, similar al teatro", al que luego, como enseguida veremos, sucedió otro, el conformado por el plano-contraplano, con el que "se dividió el espacio, se transformó una escenografía en dos" ${ }^{\prime \prime}$. Esto es, de forma muy literal, lo que veremos que sucede en la construcción del montaje de los planos subsiguientes.

Por otro lado, los movimientos de cámara siguen en travellings laterales los desplazamientos de los bailarines por el set, de manera muy convencional, y la realización va de vez en cuando alternando las tomas de estos con las del pianista, incluso recogiendo a este en algunos primeros planos de las manos; también hay una alternancia bastante convencional entre plano general, planos medios y algunos (pocos) primeros planos). Todo ello en cualquier caso fruto de decisiones de realización ajenas por completo al propio Cunningham, y que se muestran absolutamente apegadas al canon de la época de lo que era una realización televisiva en plató, a dos o tres cámaras.

La parte correspondiente a Suite for Two está a su vez subdividida en cuatro secciones. Comienza con A Meander, un solo de Carolyne Brown en el que ya se establecen de algún modo las que serán las pautas generales que sigue este trabajo en su realización. Básicamente, y tras el ya mencionado plano general de presentación en el que aparecen ambos protagonistas, el realizador alterna de forma dialogada planos de la bailarina (Carolyne Brown) con planos del músico (David Tudor), en los que vamos viendo a ella bailando, con su sombra proyectada contra la pared, generalmente en planos generales o americanos en la que la vemos de cuerpo entero, y por otro lado vemos sobre todo

5 Composed in 1958. Premiered in Dusseldorf, October 14, 1958. Ensemble Type: Variable. Instrumentation: For one or more pianists using radio and/or recordings. Comments: This work was used as music for the choreographed piece by Merce Cunningham entitled Music Walk with Dancers, with stage decors and costume design by Robert Rauschenberg. The score of Music Walk consists of a transparent sheet of plastic containing five parallel lines, ten unnumbered pages with different numbers of points, and several transparent squares containing intersecting lines drawn at various angles. Performers use these materials and follow Cage's instructions, each time creating a part using sounds to be produced at various points in and around the piano, on radios, or with auxiliary instruments (including voice) (Peters Edition EP 6739). En Hanun Farocki (2013: 90), "Plano-Contraplano. La expresión más importante de la ley del valor cinematográfico", en Desconfiar de la imágenes. Publicado originalmente como "Schuss-Gegenschuss Der wichtigste Audruck im Wertgesetz Film", en la revista Filmkritik, noviembre (1981). 
planos medios o incluso cortos de Tudor, en los que sobre todo asistimos a la ejecución con sus manos de la pieza musical sobre el teclado y las cuerdas del piano abierto. Dentro de esta estructura general de plano-contraplano, advertimos que los movimientos de la bailarina se van correspondiendo, si bien de una forma muy libre, con los ejercicios de pizzicato y percusión que el músico va realizando sobre cuerdas y teclas. Los movimientos tienden a alternar a su vez posturas procedentes del repertorio del ballet clásico, con otras que parecen en parte fruto de la improvisación libre de la bailarina, que las va descomponiendo.

Probablemente uno de los aspectos más destacables en este sentido sea esta realización con montaje dialogal en la forma de plano-contraplano, que obviamente nos remite a todo un imaginario creado por la utilización de este recurso, a lo largo de más de un siglo de historia del cine: éste, como Harun Farocki supo ver años atrás, "constituye la expresión más importante de la ley del valor cinematográfico" (Farocki, 2013: 83). Si tenemos en cuenta a continuación algunas de las características principales de este modo de montaje, veremos cómo en efecto su uso está produciendo sentido: como Farocki recuerda, en la unión sucesiva de "imágenes muy distintas entre si" (por ejemplo: manos sobre el teclado, planos medios de la bailarina) encontramos al mismo tiempo "continuidad y ruptura" (Farocki, 2013: 84). Continuidad, porque de hecho "los cortes estructuran el texto" (Farocki, 2013: 87); ruptura, porque "el curso se interrumpe, y sin embargo avanza" (Farocki, 2013: 84). Y es que, en efecto, el montaje por planocontraplano se ha terminado por convertir en el recurso narrativo más básico del llamado lenguaje audiovisual, en tanto que es "como caminar: siempre colocamos un pie delante del otro", de modo qué "si no miramos ni pensamos al respecto, alcanzamos un ritmo que permite que algo avance" (Farocki, 2013: 91).

Por otro lado, también nos encontramos en esta filmación un trabajo fundamental sobre la articulación del tiempo del relato característica de este tipo de montaje (por ejemplo: la aparente simultaneidad provocada por la reiterada alternancia entre los planos del músico y los de los bailarines, realmente colocados de manera sucesiva), puesto que esta alternancia básica del plano-contraplano en la que se funda "desvía tanto la atención del espectador que se puede hacer desaparecer el tiempo real entre los cortes" (Farocki, 2013: 92, 93).

Todo lo anterior se podía aplicar a los fragmentos que siguen a continuación, los dos solos de Merce Cunningham, Stillness y At Random: números en los que, aunque introduce alguna pequeña variación estilística (el primero por ejemplo comienza con un plano medio del bailarín al que se suma un movimiento hacia atrás hasta convertirlo en plano general, etc.), enseguida se pasa de nuevo a la realización dialogada de plano-contraplano entre bailarín y músico, descrita anteriormente. En esta ocasión, se advierte también, de modo más evidente, el sonido producido por los pies del bailarín deslizándose por el suelo; también los planos generales de Cunningham parecen algo 
más largos, pero se mantiene en todo caso el estilo de realización en contraplano con las imágenes del pianista. El final del primer solo también aporta algo de variedad, al mantener en un plano medio la imagen de Merce Cunningham arrodillado, y dirigiendo su mirada fuera de campo, mientras gira la cabeza.

Finalmente la grabación que corresponde de manera estricta a Suite for Two termina con el dueto interpretado por ambos bailarines (Brown y Cunningham). La realización se basará una vez más en la misma idea, pero esta vez la alternancia será entre el plano medio del músico (David Tudor) y el plano general, y casi siempre en movimiento, de la pareja de bailarines. La realización en esta sección es algo más dinámica, tanto en el seguimiento de los movimientos y saltos de los bailarines por la escena, como en la utilización de algunos primeros planos se seguimiento de las manos del pianista cuando realiza algunos golpes percusivos sobre las cuerdas del piano abierto.

Como hemos adelantado ya, este registro se completa con una quinta pieza que realmente no corresponde a Suite for Two, pero que al parecer fue grabada en la misma sesión que las anteriores. Se trata de Music Walk, pieza musical compuesta por John Cage muy cercana al espíritu de improvisación de la performance artística: aparece el propio Cage al comienzo en un plano general transportando una escalera con ruedas sobre la que está Carolyne Brown, de quien se toman algunos primeros planos. Después ella baja, y los dos músicos comienzan a mover primero el piano, luego otros objetos, van poniendo discos, producen ruidos y sonidos diversos, etc., mientras Brown y Cunningham bailan a su alrededor. Los dos músicos, vestidos de negro, y los dos bailarines, de blanco, parecen de algún modo habitar mundos escindidos, que transcurren en paralelo sin afectarse recíprocamente. Curiosamente la idea de la realización siguiendo el modelo del planocontraplano ha desaparecido aquí, y ha sido sustituida por una suerte de realización improvisada un tanto errática (probablemente fruto del desconocimiento de lo que va a suceder en cada momento) de lo que va pasando en escena: y es que precisamente la estructura narrativa constituida por el plano-contraplano tendrá como resultado la unión en un mismo ámbito de dos elementos que en principio pueden ser opuestos, o cuando menos ajenos el uno del otro: sin embargo mediante este tipo de montaje "los dos opuestos quedan unidos (...) en una armonía de las imágenes, como las voces de un dúo musical se entrelazan en una misma música" (Farocki, 2013: 95).

En el caso concreto de los bailarines los movimientos de estos parecen a veces corresponder a una suerte de automatismo surgido de los ensayos de los pasos de ballet, independientemente de la música o los sonidos que suenan; algunas otras veces sin embargo parecen seguir el ritmo de los discos que Tudor y Cage ponen en el tocadiscos. Las cámaras los van siguiendo, aunque hay momentos de ruptura provocados por los bailarines, como cuando se sientan bajo los focos y se quedan mirando frontalmente a cámara: la cámara lateral los coge en primer plano, pero después volvemos al plano general cuando comienzan a correr y saltar por todo el plató. La improvisación de la pieza 
desencadena momentos más dinámicos en la realización, en los que vemos primeros planos de los pies; o a unos u otros cruzándose por delante de la cámara; o cortes de realización cuando un movimiento aún no ha concluido, etc.; de tal manera que a la ordenada y en cierto modo estandarizada realización de la parte anterior parece suceder una caótica toma de "cine directo", con su consiguiente efecto de verosimilitud añadido. Quizás en alguno de estos aspectos a lo que estaríamos asistiendo aparentemente es a la lenta pero insistente "emergencia de lo real" que para muchos convierte a todo registro filmado en documento, es decir, en "huella" de un acontecimiento previo; y es que, como Farocki nos recuerda, en cine algunos de estos aspectos suelen relacionarse con la falta de destreza o el amateurismo: "Con plano-contraplano cualquiera puede hacer una película y, a la vez, si uno saber hacer un film sin plano-contraplano es considerado un amateur (...) la torpeza que queda expuesta ante la ausencia del contraplano se vincula con la pobreza formal de la práctica cinematográfica" (Farocki, 2013: 97).

\section{CONCLUSIÓN}

Según se ha podido observar, en este primer registro audiovisual conocido de una pieza de Merce Cunningham (Suite for Two, 1960) nos encontramos ya implícitas todas las tensiones que históricamente surgirán alrededor de la filmación de la danza, en tanto que supuesto documento o huella de un acontecimiento presencial primigenio: si lo miramos desde la perspectiva del giro que Derrida imprime a la fenomenología, al entender que la escritura no es mera huella de la voz (o si es huella, esta en sí misma ya constituye también un acontecimiento, una presencia por sí misma), entonces podemos concluir que el vídeo llamado Suite for Two y que aún hoy podemos ver en Internet no constituye un mero reflejo especular o una simple huella de lo que en su día fuera la pieza escénica del mismo título, sin más bien, y en virtud de su articulación sintáctica audiovisual, el visionado de este vídeo constituiría un acontecimiento en sí mismo.

En la generación de dicho acontecimiento será fundamental, como se ha visto, un recurso específicamente cinematográfico como es el montaje basado en la figura del plano-contraplano: el recurso a este y otros elementos técnicos propios del audiovisual estarían jugando un papel similar al que en el contexto de la fenomenología husserliana jugara la epojé o reducción fenomenológica, pues igualmente tiene como efecto desde el punto de vista metodológico "poner entre paréntesis lo dado" (es decir, lo que fuera la performance en sí misma) "para que aparezca más claramente el modo de darse" (es decir, el propio artefacto audiovisual).De este modo, por concluir, podemos decir que la danza filmada, de la que Suite for Two es un primerísimo caso en el conjunto de la obra de Merce Cunningham, constituye un ejemplo de lo que Derrida llamará différance. 


\section{REFERENCIAS BIBLIOGRÁFICAS}

BRANNIGAN, E. (2011). Dancefilm: Choreography and the Moving Image. New York: Oxford University Press.

COPELAND, R. (2004). Merce Cunningam. The Modernizing of the Modern Dance. Londres / Nueva York: Routledge.

CRUZ, M. (2002). Filosofía contemporánea. Madrid: Taurus.

CUNNINGHAM, M. y LESSCHAEVE, J. (2009). El bailarín y la danza. Barcelona: Global Rythm.

DODDS, S. (2004). Dance on Screen. Genres and Media from Hollywood to experimental Art. Londres: Palgrave / MacMillan.

DERRIDA, J. (1971). De la gramatología. Buenos Aires: Siglo XXI.

(2000). Introducción a “El origen de la Geometría” de Husserl. Buenos Aires: Manantial.

FAROCKI, H. (2013). "Plano-Contraplano. La expresión más importante de la ley del valor cinematográfico". En Desconfiar de la imágenes. Buenos Aires: Caja Negra.

KUHN, L. (1998). Art Performs Life: Cunningham / Monk / Jones. Minneapolis:Walker Art Center. LEVINAS, E. (2000). La huella del otro. México DF: Taurus.

PÁVEZ MUÑOZ, J. (en línea). "Jacques Derrida: huella e inscripción en el origen del sentido". En http://www.observacionesfilosoficas.net/jacquesderridahuella.htm [09/09/2015].

ROSENBERG, D. (2012). Screendance: Inscribing the Ephemeral Image. New York: Oxford University Press.

SAN MARTÍN, J. (2008). La fenomenología de Husserl como utopía de la razón. Madrid: Biblioteca Nueva.

VAUGHAN, D. (1997). Merce Cunningham Fifty Years. New York: Aperture.

VILLOTA TOYOS, G. (2008). "Buscando la verdad (filmada) del cuerpo que habla”. Zehar (Donostia) 64.

(2015). “Vindicación de la huella en Merce Cunningham (Danza y registro audiovisual en tres etapas históricas, 1960-1993)". En Performance: historia, disciplina y recepción, Juan Albarrán e Iñaki Estella (eds.). Madrid: Ed. Brumaria. 
